\title{
Comparison of Enamel Surface Roughness after Brushing with Herbal and Non-herbal Toothpastes
}

\author{
Suwanna Korsuwannawong ${ }^{1}$, La-ongthong Vajrabhaya ${ }^{2}$, Chayada Teinchai $^{3}$, Weena Salee ${ }^{4}$
}

\begin{abstract}
Aims: The present study was undertaken to compare the effect of herbal and non-herbal toothpastes on the enamel surface of human permanent maxillary premolars by measuring surface roughness and SEM observation and analyzing the element content in both types of toothpaste. Materials and methods: Forty specimens (10/group) were brushed using distilled water, non-herbal toothpaste, or two different herbal toothpastes on the buccal surfaces with their respective group's toothpaste or distilled water. The specimens were brushed twice a day; 2 minutes per time in the morning and evening routinely for 15 days. The roughness average (Ra value) was measured using a Profilometer. SEM observation and element content in both types of toothpaste were also determined. The data was analyzed using the paired samples $T$-test, the Kruskal-Wallis test, and the Mann-Whitney $U$ test at a significance level of $5 \%$.

Results: The enamel surface roughness after brushing with non-herbal toothpastes was $0.049 \mu \mathrm{m}$ while the other two herbal toothpastes were 0.095 and $0.071 \mu \mathrm{m}$ respectively. Ra value of enamel in both herbal toothpastes groups were higher than the non-herbal toothpaste $(p=0.000)$. While Ra values of non-herbal toothpaste after brushing for 15 days were not significant difference from distilled water, control group. SEM revealed both herbal toothpaste resulted in rougher enamel surface than non-herbal toothpaste and distilled water. The volume of elements in each toothpaste was relatively similar.

Conclusion: Although toothpastes containing herbal substances increase enamel surface roughness, it is below the upper limit of enamel roughness $(0.2 \mu \mathrm{m})$ to cause bacterial accumulation in the clinic.

Clinical significance: Herbal toothpaste brushing has no significant pathological effect on enamel.

Keywords: Brushing, Herbal toothpaste, Non-herbal toothpaste, Surface roughness.

World Journal of Dentistry (2020): 10.5005/jp-journals-10015-1732
\end{abstract}

\section{INTRODUCTION}

Abrasion is the mechanical wearing of dental hard tissue and commonly affects cervical tooth structure. This noncarious tooth loss typically involves the enamel, dentine, and may involve the cementum, resulting in gingival recession. The main predisposing factors for abrasion are the toothbrushing method and the type of toothpaste used.

The type of toothbrush, vigorous brushing force, and brushing technique can result in severe abrasion. A horizontal brushing technique combined with a medium or hard bristled toothbrush exceeding 2 minutes brushing time can cause abrasive lesions, especially at the cervical area. ${ }^{1}$ The force from manual toothbrushing is higher compared with using an automatic toothbrush and increases the amount of abrasion of sound and eroded dentine. ${ }^{2}$

Toothpaste is an important component in the etiology of abrasion. Most toothpastes contain abrasive agents for cleaning, maintaining, and improving tooth health. There are two types of toothpaste commercially available; synthetic and herbal formulations. Synthetic toothpastes typically contain abrasive agents, such as calcium phosphate, calcium carbonate, silica or hydrated silica for removing debris and stains. ${ }^{3}$ The relative dentine abrasivity (RDA) is the standardized measurement of toothpaste abrasivity. ${ }^{4}$ A dentifrice with an RDA score less than 100 is safe for preventing enamel abrasion. ${ }^{5}$

Some people prefer herbal toothpastes because their components come from natural plants and avoid the sideeffects of allergy irritation from synthetic formulations. Herbal toothpastes are available as toothpowders and toothpastes with different formulations. However, some consumers suspect that

\footnotetext{
1,3 Research Office, Faculty of Dentistry, Mahidol University, Ratchathewi, Bangkok, Thailand

${ }^{2}$ Endodontics Section, College of Dental Medicine, Rangsit University, Mueang, Pathum Thani, Thailand

${ }^{4}$ School of Dental Assistant, Faculty of Dentistry, Mahidol University, Ratchathewi, Bangkok, Thailand
}

Corresponding Author: Suwanna Korsuwannawong, Research Office, Faculty of Dentistry, Mahidol University, Ratchathewi, Bangkok, Thailand, Phone: +662-200-7620, e-mail: suwanna.aut@mahidol.ac.th How to cite this article: Korsuwannawong S, Vajrabhaya L, Teinchai C, et al. Comparison of Enamel Surface Roughness after Brushing with Herbal and Non-herbal Toothpastes. World J Dent 2020;11(3):215-220. Source of support: This research project is supported by Faculty of Dentistry, Mahidol University in 2018

Conflict of interest: None

herbal toothpastes are abrasive to tooth structure. The study of Benjavongkulchai et al. ${ }^{6}$ revealed that herbal toothpowder had the RDA value more than herbal toothpaste formulation of the same manufracturer. Most commercial toothpastes contain a combination of abrasive ingredient, detergent and therapeutic agents. However, the abrasivity of tooth structure by using contemporary herbal toothpaste is currently not understood. The purpose of this study was to investigate:

- The abrasive effect of herbal toothpastes compared with a non-herbal toothpaste on the enamel surface of permanent teeth by measuring the surface roughness with profilometer and SEM observation. 
- The element type in the composition of both types of toothpaste by EDX analysis.

\section{Materials and Methods}

Forty maxillary premolar teeth were used in this study. The collected teeth were extracted for orthodontic reasons at the Oral Surgery Clinic at the Faculty of Dentistry, Mahidol University. The specimen inclusion criteria were that the buccal surfaces of the maxillary first or second premolar teeth were without caries or cracks. This study was approved by The Ethics Review Committee for Human Research, Faculty of Dentistry and Faculty of Pharmacy Mahidol University, Thailand (Certificate of Exemption COE. No. MU-DT/ PY-IRB 2018/010.2702).

The teeth were randomly divided into four groups $(n=10)$ according to the toothpaste used. Group I: brushed with distilled water (DW), group II: brushed with non-herbal toothpaste (NHT), group III: brushed with herbal toothpaste 1 (HT1) and group IV: brushed with herbal toothpaste 2 (HT2). The active ingredients and the toothpaste base are shown in Table 1.

\section{Tooth Preparation}

The teeth that met the study criteria were decoronated at the cementoenamel junction (CEJ) in a mesiodistal direction using a low-speed saw and diamond blade. An adhesive paper was placed on a mixing glass slab and the buccal enamel surfaces were affixed to the paper. A plastic ring encircling the specimen was affixed to each adhesive paper. Self-cured acrylic resin was poured into the mold to a height of $0.75 \mathrm{~cm}$ and left for 10 minutes until the resin hardened. The paper on the buccal surface of each specimen was then removed and the tooth was sanded with 600, 800, 1000, and 2000 grit sandpaper. During sanding, the thickness of each specimen was controlled; the enamel could not be removed greater than $0.1 \mathrm{~mm}$ and the area of enamel was approximately $3 \times 5 \mathrm{~mm}$, measured using Mitutoyo Digital Vernier Calipers. (Mitutoyo, Mitutoyo Corporation, Kawasaki, Japan.) After sanding, the specimens were kept in artificial saliva, ${ }^{7}$ in a $37^{\circ} \mathrm{C}$ incubator during the study period.

\section{Surface Roughness Evaluation}

The initial surface roughness $(\mathrm{Ra})$ value of each specimen was measured using a profilometer. (Talysurf series 2, Tylor-Hobson Ltd., Leicester, England) with an evaluation length of $1.25 \mathrm{~mm}$ ( $0.25 \times 5 \mathrm{~mm}$ cutoff length) per ISO $4288 .^{8}$ Three measurements were performed per sample on three different surface areas. The average of the three measurements were calculated and analyzed.

\section{Toothbrushing}

After the initial surface roughness measurement, the specimens were brushed with their respective group's toothpaste or distilled water. The specimens were brushed twice a day for 2 minutes in the morning and evening for 15 days. The weight of the toothpaste at each brushing was $0.1 \mathrm{~g}$ mixed with $100 \mu \mathrm{L}$ of distilled water and was applied on the buccal tooth surface. The specimens were brushed using an automatic toothbrushing device with $7600 \mathrm{rpm}$ (Braun Oral-B Vitality ${ }^{\mathrm{TM}}$ Precision Clean D12.013, Braun GmbH Co, Kronberg, Germany) (Fig. 1). The specimens were kept in $25 \mathrm{~mL}$ artificial saliva and incubated in a $37^{\circ} \mathrm{C}$ shaker incubator for the duration of the experiment.

\section{SEM Analysis}

All specimens in each group were analyzed by SEM (JSM-6610LV, JEOL, Tokyo, Japan). The specimens that were properly sputtercoated with gold were selected for SEM observation at $1000 \times$ magnification.

\section{EDX Analysis}

The three experimental toothpastes were analyzed by EDX (Oxford X-MAX, England). Each toothpaste specimen $(0.1 \mathrm{~g})$ was sputtercoated with gold. Then each specimen was subjected to EDX with the first peak of element standard set to " 0 ". Subsequently, the specimen was analyzed using INCA software (Oxford x-Max,

Table 1: Active ingredients and bases of three toothpastes in the study

\begin{tabular}{|c|c|c|}
\hline Toothpaste (manufacture) & Active ingredient & Base \\
\hline $\begin{array}{l}\text { 1. Non-herbal toothpaste, NHT, } \\
\text { Trade name: Great regular flavor } \\
\text { (Colgate-Palmolive (Thailand) } \\
\text { Co., Ltd. Bangkok, Thailand) }\end{array}$ & $\begin{array}{l}\text { - Dicalcium phosphate dehydrate } \\
\text { - Sodium monofluorophosphate } \\
\text { - Tetrasodium pyrophosphate }\end{array}$ & $\begin{array}{l}\text { - Sodium lauryl sulfate } \\
\text { - Sodium saccharin } \\
\text { - Sorbitol } \\
\text { - Flavor }\end{array}$ \\
\hline $\begin{array}{l}\text { 2. Herbal toothpaste, HT1, Trade } \\
\text { name: Total Charcoal (Colgate- } \\
\text { Palmolive (Thailand) Co., Ltd. } \\
\text { Bangkok, Thailand) }\end{array}$ & $\begin{array}{l}\text { - } \text { Hydrate silica } \\
\text { - } \text { Sodium fluoride } \\
\text { - } \text { Triclosan } \\
\text { - } \text { Carrageenan } \\
\text { - Charcoal powder } \\
\text { - } \text { PVM/MA Copolymer }\end{array}$ & $\begin{array}{l}\text { - Sodium lauryl sulfate } \\
\text { - Sodium saccharin } \\
\text { - Sorbitol } \\
\text { - Flavor }\end{array}$ \\
\hline \multirow[t]{2}{*}{$\begin{array}{l}\text { 3. Herbal toothpaste, HT2, Trade } \\
\text { name: Original formula (Twin } \\
\text { Lotus Co., Ltd. Samut Prakan, } \\
\text { Thailand) }\end{array}$} & $\begin{array}{l}\text { - Cuttlefish bone } \\
\text { - Toothbrush tree }\end{array}$ & $\begin{array}{l}\text { - Sorbitol (natural) origin from cassava } \\
\text { - Sodium lauryl sulfate (natural origin } \\
\text { from coconut oil) }\end{array}$ \\
\hline & $\begin{array}{l}\text { - Clinacanthus nutans } \\
\text { - Orange jessamine } \\
\text { - Peppermint oil } \\
\text { - Menthol } \\
\text { - Eucalyptus oil }\end{array}$ & $\begin{array}{ll}\text { - } & \text { Flavor } \\
\text { - Sodium benzoate (food grade) } \\
\text { - } \text { Glyceline }\end{array}$ \\
\hline
\end{tabular}




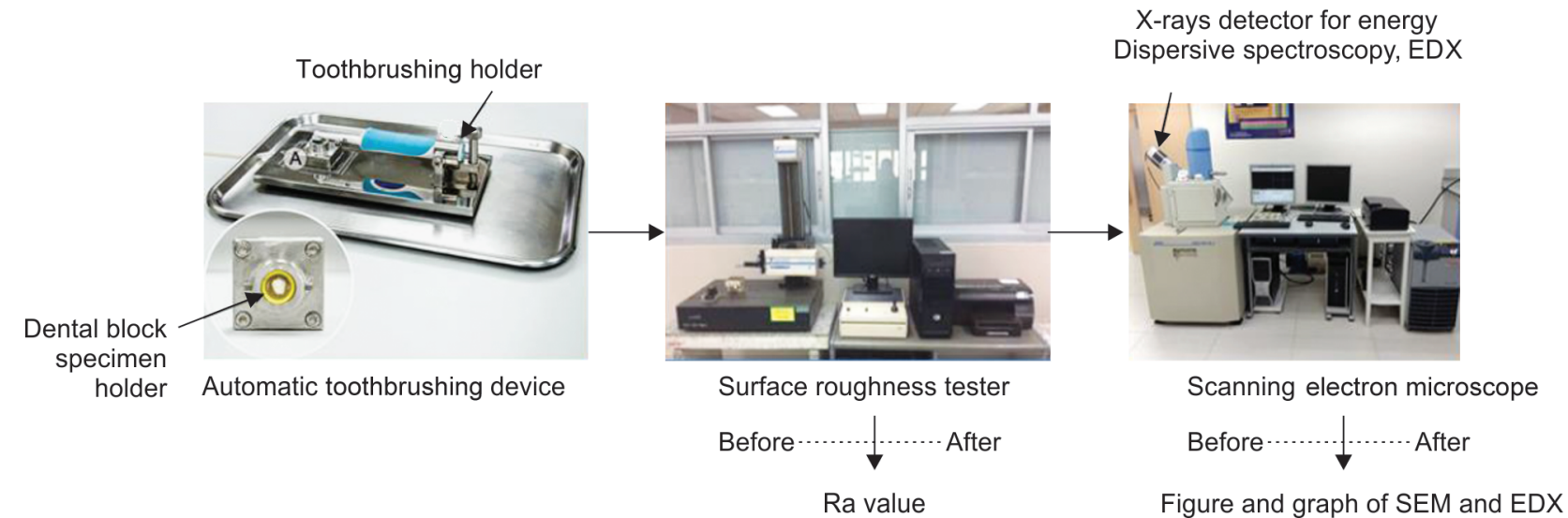

Fig. 1: Procedural photographs of the study

Table 2: Enamel surface roughness before and after toothbrushing in the experimental groups

\begin{tabular}{|c|c|c|c|}
\hline \multirow[b]{2}{*}{ Group } & \multicolumn{2}{|c|}{ Enamel surface roughness (Ra value) $[R a \pm S D(\mu m)]$} & \multirow[b]{2}{*}{$p$ value among groups } \\
\hline & Initial & After brushing for 15 days & \\
\hline \multirow[t]{2}{*}{ Distilled water (DW) } & & $p=0.263$ & \\
\hline & $0.035 \pm 0.014$ & $0.042 \pm 0.012$ & \\
\hline \multirow[t]{2}{*}{ Non-herbal toothpaste (NHT) } & & $p=0.440$ & DW vs NHT ( $p=0.191)$ \\
\hline & $0.034 \pm 0.011$ & $0.049 \pm 0.013$ & \\
\hline \multirow[t]{2}{*}{ Herbal toothpaste 1 (HT1) } & & $p=0.000^{*}$ & DW vs HT1 $\left(p=0.000^{*}\right), \mathrm{NHT}$ vs HT1 $\left(p=0.000^{*}\right)$ \\
\hline & $0.032 \pm 0.001$ & $0.095 \pm 0.007$ & \\
\hline \multirow[t]{2}{*}{ Herbal toothpaste 2 (HT2) } & & $p=0.000^{*}$ & $\begin{array}{l}\text { DW vs HT2 }\left(p=0.000^{*}\right) \text {, NHT vs HT2 }\left(p=0.000^{*}\right) \text {, } \\
\text { HT1 vs HT2 }(p=0.107)\end{array}$ \\
\hline & $0.034 \pm 0.011$ & $0.071 \pm 0.012$ & \\
\hline
\end{tabular}

*Indicates significant difference $p<0.05$

England) to examine its localized elemental distribution at the microscopic scale. After capturing the images and scanning the specimen by EDX, the results are shown as the EDX spectrum of the elemental composition in the toothpaste samples.

The procedures of the study were shown in Figure 1.

\section{Statistical Analysis}

The difference in the mean roughness ( $\mathrm{Ra}$ ) values before and after brushing with the respective groups toothpaste or distilled water were evaluated using the paired sample $t$-test. The Kruskal-Wallis test was used to compare the mean roughness after brushing with the three different toothpastes. The Mann-Whitney $U$ test was used to determine significant differences between the means when the Kruskal-Wallis test result was significant. The significance level was set at $p \leq 0.05$. The Statistical Packages for Windows (SPSS Inc., Chicaco II) was used for all statistical analyzes.

\section{Results}

\section{Surface Roughness Evaluation}

The results indicated that the initial pre-brushing Ra values and after 15 days brushing in all four groups; DW group, NHT group, HT1 group and HT2 group were $0.035,0.034,0.032$ and $0.034 \mu \mathrm{m}$ and $0.042,0.049,0.095$ and $0.071 \mu \mathrm{m}$, respectively (Table 2 ). The initial Ra values of all groups were not significantly different $(p=0.569)$. The initial Ra values and those after brushing with DW and NHT were not significantly different ( $p=0.263, p=0.440$, respectively). In contrast, the Ra values in the HT1 and HT2 groups significantly increased after brushing ( $p=0.000, p=0.000$ respectively). However, the Ra value of the NHT brushing group was not significantly different from the DW brushing group after brushing for 15 days ( $p=0.191$ ). The two herbal toothpaste groups' Ra values after brushing were significantly higher compared with those of DW and NHT groups $(p=0.000)$, but not significantly different from each other $(p=0.107)$.

\section{SEM Analysis}

The SEM images (Fig. 2) revealed smooth enamel surfaces in all groups before brushing. After brushing, the enamel surface of the DW group and the NHT group remained smooth with both images demonstrating scratches. However, brushing with two herbal toothpastes resulted in an enamel surface that was rougher compared with brushing with DW or NHT group. In contrast, the enamel surface roughness in the two herbal toothpaste brushing groups (HT1 and HT2) was similar. The HT1 surface has a more pebbled appearance from more enamel being removed, which is reflected in its higher Ra value, while the HT2 surface has deeper scratches with some enamel loss.

\section{EDX Analysis}

The elements and their atomic\% in the three toothpastes detected by EDX analysis are shown in Figure 3. All three toothpaste contained $\mathrm{C}, \mathrm{F}, \mathrm{O}, \mathrm{Na}, \mathrm{Si}, \mathrm{S}$, and $\mathrm{Ca}$ in different percentages. Both herbal toothpastes contained $0.13-0.14 \% \mathrm{Ti}$. Although NHT and $\mathrm{HT} 2$ contained $\mathrm{F}^{-}$, $\mathrm{HT} 1$ did not. 


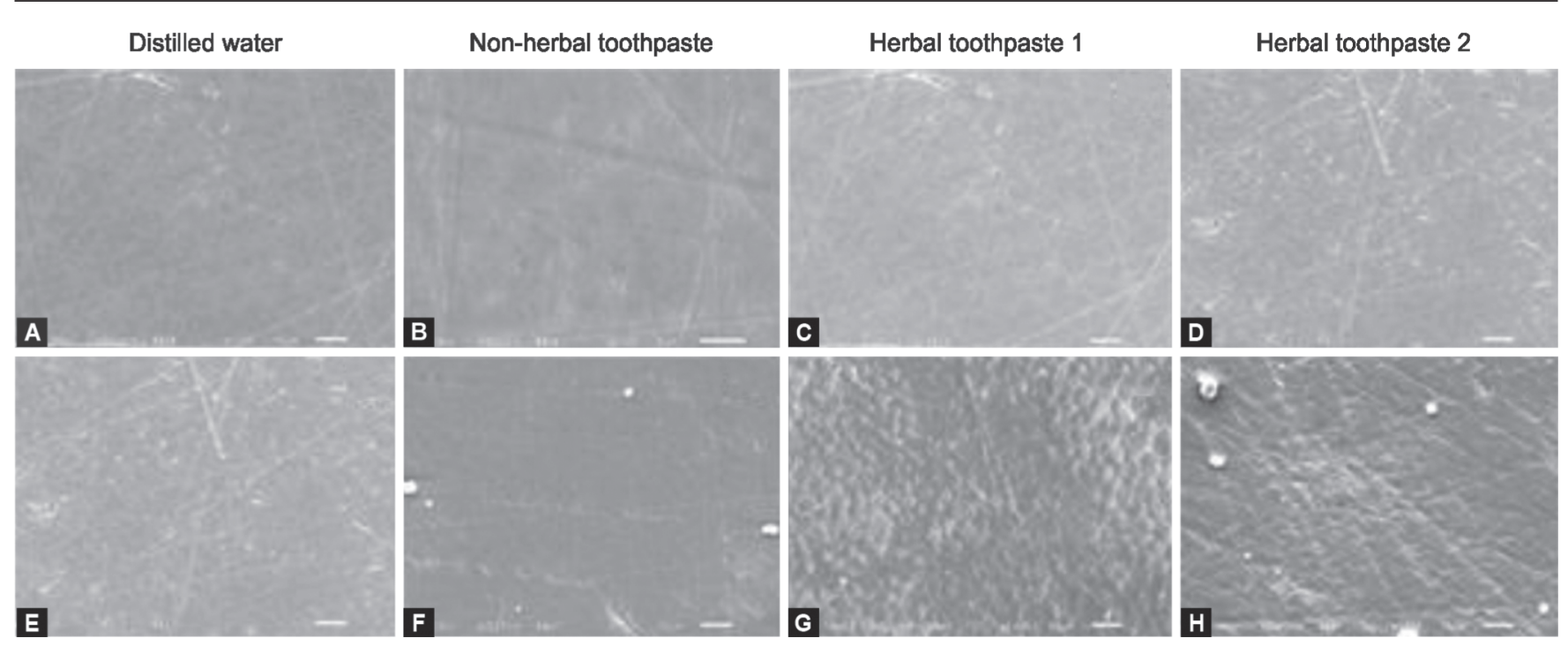

Figs $2 \mathrm{~A}$ to $\mathrm{H}$ : Scanning electron microscopy of the enamel surface before brushing (A to $D)$ and after brushing (E to $H)(1000 \times$ magnification)
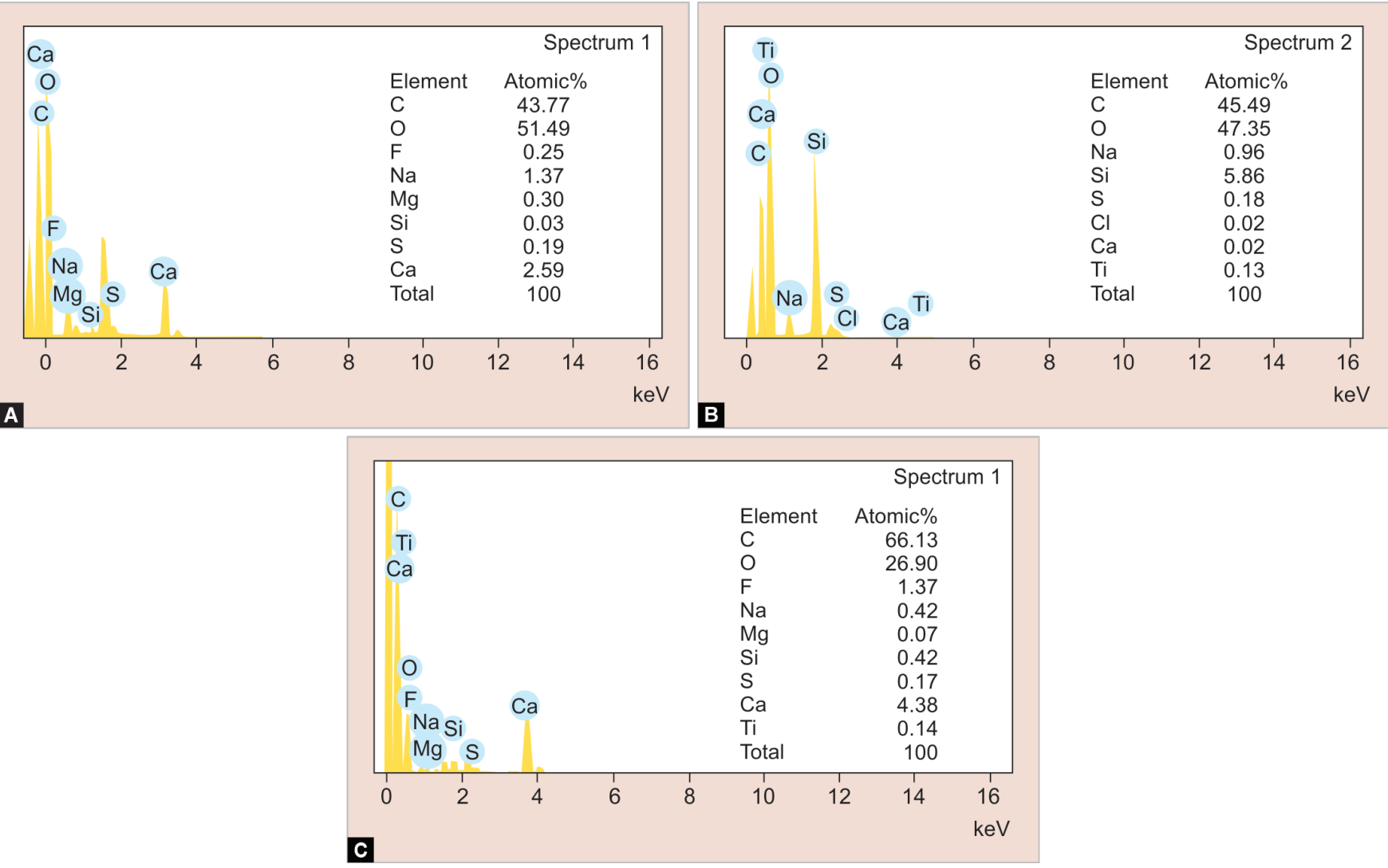

Figs 3A to C: EDX analysis of herbal and non-herbal toothpaste samples: (A) Non-herbal toothpaste; (B) Herbal toothpaste 1; (C) Herbal toothpaste 2

\section{Discussion}

The present study revealed that the Ra values before and after brushing with distilled water (control group) and non-herbal toothpaste groups were not significantly different ( $p=0.440$ and 0.263 , respectively). However, the Ra value of the enamel increased after brushing with the two herbal toothpastes HT1 and HT2, and were significantly different from before brushing $(p=0.000$ and 0.000 , respectively). Pertiwi et al. ${ }^{9}$ also concluded their study that toothbrushing with charcoal toothpaste increase surface roughness of enamel more than non-herbal one. In contrast to the study of Aggarwal et al. ${ }^{10}$ demonstrated that herbal toothpaste were less abrasive on enamel compared to non-herbal toothpaste. Moreover, the enamel after brushing with both herbal toothpastes demonstrated more roughness compared with the non-herbal toothpastes and the control groups. The SEM images were 
consistent with the surface roughness results. The SEM images demonstrated that the enamel in both herbal toothpaste groups were not as smooth as those in the distilled water and non-herbal toothpaste groups.

The EDX analysis indicated that the atomic\% of the three standard elements $\mathrm{C}, \mathrm{O}$, and $\mathrm{Na}$ in the tested toothpastes $\mathrm{NHT}, \mathrm{HT} 1$, and $\mathrm{HT} 2$ were $96.63 \%, 94.21 \%$, and $93.45 \%$, respectively. The volume of these elements in each toothpaste was relatively similar. However, the atomic\% of $\mathrm{F}^{-}$in the non-herbal toothpaste (NHT) and herbal toothpaste (HT2) was $0.25 \%$ and $1.37 \%$, respectively. The amount of $\mathrm{F}^{-}$in the toothpaste did not prevent the surface roughness from increasing after brushing. ${ }^{11}$ In contrast, Ganss et al., ${ }^{12}$ found that conventional $\mathrm{NaF}$ toothpaste prevented enamel erosion from acidmediated surface softening and stimulated remineralization of the erosive lesion. The higher amount of $\mathrm{Si}(5.86 \%)$ in HT1 may account for the higher Ra value and pebbled surface SEM image compared with the other groups. Hydrated silica is the active ingredient in HT1 for the purpose of stain and plaque removal.

The present study revealed that both herbal toothpaste groups had higher Ra values (0.095 and $0.071 \mu \mathrm{m})$ after toothbrushing compared with the non-herbal toothpaste and distilled water groups $(0.049$ and $0.044 \mu \mathrm{m})$. However, the increased Ra value was less than the threshold Ra of enamel of $0.2 \mu \mathrm{m}$. The threshold Ra is the surface roughness of an intraoral hard surface that significantly increases in vivo supra-plaque formation. ${ }^{13}$ An Ra equal or below $0.2 \mu \mathrm{m}$ would be expected to not impact bacterial retention. The initial plaque formation on the roughness of enamel surface results from the initiation of microorganism adhering and proliferating on that area. ${ }^{14}$ Plaque formation results in the development of caries and periodontal inflammation.

RDA is another factor influencing enamel surface roughness. The acceptable standard RDA is 100, which reflects a mechanism abrasive level. A toothpaste with a high RDA value can increase enamel surface roughness. ${ }^{5}$ In opposite to the study of Liljeborg et al. ${ }^{15}$ revealed that a toothpaste with a lower RDA value created a surface roughness more than a higher RDA value. The present study RDA value of test toothpastes (NHT and HT1 and HT2) obtained from the manufacturer were 68,70 and 38 respectively. ${ }^{16}$ Not only abrasive materials but also other components in the toothpaste formula may cause more enamel surface roughness in the HT2 than NHT.

The brushing force in the present study was controlled using an automatic toothbrush instead of a manual toothbrush. The same brushing force was applied on the enamel surface in every group of our study. The amount of toothpaste and the brushing time were also controlled at the same weight and time. People commonly brush their teeth twice a day; in the morning and at night, typically for 2 minutes/time. All the teeth in the mouth are brushed during the typical brushing time of 2 minutes. Thus, brushing one tooth surface can be assumed to take 5 seconds. ${ }^{9}$ Thus, we assumed that brushing a tooth each day takes 10 seconds. Each tooth in our study was brushed 240 seconds per day for 15 days, which would be equivalent to 12 months. The teeth were kept in artificial saliva at $37^{\circ} \mathrm{C}$ during the experiment to simulate the clinical situation.

The herbal toothpastes in the present study resulted in a greater increase in enamel surface roughness greater compared with the non-herbal toothpaste. However, our findings do not imply that increased enamel roughness we found would cause a pathological lesion. Moreover, the RDA values of the tested toothpastes in our study are acceptable in terms of safety because they are below the upper limits given by DIN/ISO standard $11609 .{ }^{17}$ However, a patient with an erosive challenge, who commonly eats acidic food, should be aware not to brush immediately after eating such food to prevent damage to the softer enamel at the CEJ.

There are some limitations in our study. First, the sound maxillary premolar teeth were included in this experiment but severe tooth wear such as eroded enamel or softened enamel regularly occur in the oral cavity. Whether herbal toothpastes affect such enamel is the further study. Second, in the condition of the oral cavity, patients have Class V cavities with restorations. So the effect of herbal toothpaste on the variety of Class $V$ restorations is the another future study.

\section{Conclusion}

The herbal toothpastes are more abrasive compared than nonherbal toothpaste in terms of enamel surface roughness. However, the development of a pathological lesion on enamel based on this increased roughness should not be expected because the enamel loss is below the limit required to initiate bacterial adhesion and colonization.

\section{Clinical Significance}

Herbal toothpaste brushing has no significant pathological effect on enamel.

\section{References}

1. Ganss C, Schlueter N, Preiss S, et al. Tooth brushing habits in uninstructed adults - frequency, technique, duration and force. Clin Oral Investig 2009;13(2):203-208. DOI: 10.1007/s00784-008-0230-8.

2. Wiegand A, Burkhard JP, Eggmann F, et al. Brushing force of manual and sonic toothbrushes affects dental hard tissue abrasion. Clin Oral Investig 2013;17(3):815-822. DOI: 10.1007/s00784-012-0788-z.

3. Grace XF, Darsika C, Sowmya KV, et al. Preparation and evaluation of herbal dentifrice. Int Res J Pharm 2015;6(8):509-511. DOI: 10.7897/2230-8407.068102.

4. John SS, White DJ. History of the development of abrasivity limits for dentifrices. J Clin Dent 2015;26(2):50-54.

5. Addy M, Hughes J, Pickles MJ, et al. Development of a method in situ to study toothpaste abrasion of dentine. comparison of 2 products. J Clin Periol 2002;29(10):896-900. DOI: 10.1034/j.1600051x.2002.291004.x.

6. Benjavongkulchai E, Tamsaitom S, Schemehorn BR, et al. Cleaning ability and abrasity of dentrifices in Thailand. J Dent Assoc Thai 2000;50(5):372-376.

7. McKnight-Hanes $C$, Whitford GM. Fluoride release from three glass ionomer materials and the effects of varnishing with or without finishing. Caries Res 1992;26(5):345-350. DOI: 10.1159/000261466.

8. The International Organization for Standardization. Geneva: ISO 4288. Geometrical Product Specifications (GPS)-Surface texture: Profile method-Rules and procedures for the assessment of surface texture. 1996(en) [cited 2018 Oct 19];ISO. Available from: https://www.iso.org/ obp/ui/\#iso:std:iso:4288:ed-2:v1:en.

9. Pertiwi UI, Eriwati YK, Irawan B. Surface changes of enamel after brushing with charcoal toothpaste. J Phys Conf Ser 2017. 884. DOI: 10.1088/1742-6596/884/1/012002.

10. Aggarwal A, Krishan S, Midha V, et al. Abrasive action of herbal vs non-herbal toothpaste: a profilometric analysis. J Pharm Biomed Sci 2017;7(5):132-135.

11. Rios $D$, Magalhães $A C$, Polo ROB, et al. The efficacy of a highly concentrated fluoride dentifrice on bovine enamel subjected to erosion and abrasion. J Am Dent Assoc 2008;139(12):1652-1666. DOI: 10.14219/jada.archive.2008.0107. 
12. Ganss C, Lussi A, Grunau O, et al. Conventional and anti-erosion fluoride toothpastes: effect on enamel erosion and erosion-abrasion. Caries Res 2011;45(6):581-589. DOI: 10.1159/000334318.

13. Bollen CM, Papaioanno W, Van EJ, et al. The influence of abutment surface roughness on plaque accumulation and periimplant mucositis. Clin Oral Implants Res 1996;7(3):201-211. DOI: 10.1034/j.1600-0501.1996.070302.x.

14. Brecx M, Theilade J, Attström R. An ultrastructural quantitative study of the significance of microbial multiplication during early dental plaque growth. J Periodontal Res 1983;18(2):177-186. DOI: 10.1111/j.1600-0765.1983.tb00351.x.
15. Liljeborg A, Tellefsen G, Johannsen G. The use of a profilometer for both quantitative and qualitative measurements of toothpaste abrasivity. Int J Dent Hyg 2010;8(3):237-243. DOI: 10.1111/j.1601-5037.2009.00433.x.

16. All About Whitening Toothpastes [Internet]. Zweig A: A private dental practice in Beverly Hills [reviewed 2012 Apr 21]. Available from: http://www.teethwhiteningreviews.com/artman/publish/whiteningtoothpastes-exposed.php.

17. The International Organization for Standardization. Geneva: ISO 11609. Dentistry -Dentifrices - Requirements, test methods and marking. 2017(en). [cited 2018 Oct 19]; ISO. Available from: https:// www.https://www.iso.org/obp/ui/\#iso:std:iso:11609:ed-3:v1:en. 